\title{
A dimensão estética no ensino de geografia: uma contribuição à renovação da geografia escolar
}

\author{
The aesthetic dimension in geography teaching: a contribution to the \\ renewal of school geography
}

Élvis Christian Madureira Ramos'

\begin{abstract}
RESUMO
É cada vez mais frequente o uso e a menção de obras relacionadas às artes visuais, literárias e poéticas em recursos didáticos dos conteúdos da geografia escolar, mas que as restringe a instrumentos ilustrativos ou apenas referencial temático. A questão que se coloca é: Como essa interface nas aulas de geografia pode ser explorada além de um efeito pictórico e/ou tópico? Uma guinada que supere essas reduções é a busca da valorização da dimensão estética no ensino de geografia, justamente aquilo que possibilita uma confluência de arte e geografia. Em realidade, a dimensão estética costuma ser esquecida ou desprezada dentro da própria geografia enquanto ciência ou na geografia de contexto escolar. Contudo, ela é parte do cotidiano, do universo sensível e imaginativo dos sujeitos sociais. Este estudo busca tornar evidente sua importância no ensino de geografia e, ao mesmo tempo, explorar um sentido mais largo para o uso das linguagens da arte como um recurso que, mediado pelo professor, possibilita o exercício da imaginação geográfica.
\end{abstract}

Palavras-chaves: Arte; Ensino de geografia; Estética; Geografia

\section{ABSTRACT}

The use and mention of visual, literary and poetic works of art in school geography teaching materials have increasingly grown, but in a way that restricts them to illustrative instruments or mere thematic references. The question is, how can this interface in geography lessons be explored further than this pictorial and/or topic approach? A twist that can overcome such reductions is to pursue the appreciation of the aesthetic dimension in teaching geography, precisely that which allows art and geography to align. In fact, the aesthetic dimension is often forgotten or neglected within geography itself as both a science and an educational field. However, art is part of social subjects' everyday life and sensitive and imaginative universe. This study seeks to make its importance evident in the teaching of geography and, at the same time, explore a broader sense for the use of its various languages as resources to be mediated by the teachers so that students can exercise their geographical imagination.

Keywords: Art; Aesthetics; Geography; Geography teaching

I Secretário da Educação do Estado de São Paulo. Doutorado em Geografia pela Universidade Estadual Paulista (UNESP-PP). Membro da Diretoria Executiva da Associação dos Geógrafos Brasileiros (AGB). E-mail; solelvis@gmail.com ORCID: https://orcid.org/0000-0002-6245-6850 


\section{INTRODUÇÃO}

Este estudo visa explorar o uso das linguagens da arte no ensino de geografia e se situa numa das dimensões da educação geográfica que se relaciona com as formas de representação e linguagens no ensino e aprendizagem. Contudo, mais que formular uma proposta didático-pedagógica mais no ar do que na terra, ou desenraizada de fundamentos, buscou-se aqui refletir sobre as concepções que justificam e ao mesmo tempo abrem um campo de possibilidades práticas e enriquecedoras no ensino de geografia e, quiçá, participe do esforço de renovação rumo a uma geografia escolar mais abrangente quanto ao reconhecimento de outros saberes, sentidos e experiências geográficas.

A princípio, o uso ou a menção de trabalhos artísticos como ancoragens para a reflexão sobre conteúdos geográficos parecem indicar a tendência a uma abertura consciente a outras formas de recursos e/ou linguagens no ensino de geografia, como também um entendimento quanto a um certo esgotamento às formas de tratamento dos vários aspectos do espaço geográfico na escola. Isso vai desde a repetição contínua e irrefletida dos tratamentos dados aos conteúdos até as estratégias de ensino e uso das formas de representações tradicionais (figuras, gráficos, mapasi).

Esse continuísmo ou engessamento do ensino de geografia, por sua vez, encontra resistências e a busca contínua por novas metodologias e abordagens didático-pedagógicas, mais enriquecedoras e criativas. Porém, é também preciso destacar que o professor de geografia (e não somente ele) se vê cada vez mais preso num tipo de rigidez curricular e metodológica. Submetido a uma hierarquia de poder consubstanciada em ideologias e diretrizes que se impõe de cima para baixo, que refreiam sua criatividade e fazer pedagógico, o que se reflete em grande parte das vezes numa prática simplesmente repetitiva e padronizada em sala de aula. 
Todavia, a inserção da arte no ensino de geografia é parte desses esforços de renovação, e já dá seus primeiros passos, e ao mesmo tempo suscita discussões pertinentes à sua ancoragem teórico-metodológica. Afinal, que perspectivas, valores e contribuições profícuas poderia a confluência artegeografia trazer em situações de aprendizagem e interações no microespaço da sala de aula ou, num sentido contributivo, como uma abordagem renovada dos conteúdos solidamente institucionalizados (ou até reificados) na geografia escolar poderia contribuir?

Claro que o que está em jogo em última instância é o desafio que se impõe a todo professor de geografia, que é o de tornar o "aprender geografia" algo criativo, espontâneo e participativo. Aqui o binômio arte-geografia se transforma numa abordagem didático-pedagógica promissora para este fim.

Porém, queremos defender que, bem mais que um acessório ilustrativo ou "diferente", o elemento artístico valoriza o elemento estético no ensino de geografia como uma oportunidade para o educando experienciar as espacialidades/geograficidades sob outros aspectos qualitativos. Perspectiva e prática, o que não concorre com o conteúdo programático hegemônico na geografia escolar e nem o substitui. Esta união oferece uma maneira criativa e revolucionária para o aluno usufruir de outros sentidos do espaço.

Da mesma forma que a geografia não se reduz a cartografia, também não se pretende reduzir ou subordinar a geografia a um trabalho artístico. O que se busca com essa interface não é a redução de uma coisa a outra. A particularidade que se almeja no âmbito da geografia escolar é ampliar as possibilidades do enriquecimento do olhar geográfico por meio da experiência estética sob a mediação do professor em sala de aula.

Não obstante, este trabalho não visa abordar todas as possíveis implicações da dimensão estética no ensino de geografia; não que elas não mereçam atenção, mas porque ainda não são totalmente previsíveis. O intuito aqui é mais de ajudar a semear algumas proposições que favoreçam uma discussão ampla sobre o ensino de geografia e suas linguagens. Ficaremos 
satisfeitos se ao menos contribuirmos para trazer elementos teóricometodológicos, além de algumas experiências práticas que ampliem significativamente o conhecimento sobre este tema.

Na primeira parte deste trabalho apresentamos os aspectos que informam e dão extensão à temática da arte e sua dimensão estética. Depois estudaremos como é possível fazer a interface arte-geografia e sua contextualização em termos daquilo que mereceria o status de essencial na articulação geografia, arte e ensino. Na última parte, são descritas duas experiências em sala de aula com base no uso da linguagem artística e outras referências no campo da arte. É prudente enfatizar que esta última parte não visa guiar para um modelo ou uma sequência didática ideal, e sim mostrar justamente as dificuldades e potencialidades que surgem quando se materializa essa interface com educandos no ensino básico.

\section{A ESTÉTICA DA ARTE}

Afinal, o que é a arte? Responder esta pergunta é entrar num terreno cheio de controvérsias, pois, além de se fazer referência a uma forma de trabalho e expressividade ampla e irrestrita do espírito humano, o status do que é arte varia no espaço e no tempo (COLI, 1981), ou seja, se uma criação pode ser chamada de arte depende dos critérios e/ou regras que variam nas épocas e em contextos sociais, e até mesmo o lugar exerce uma influência nissoii.

Seja como for, a arte se faz no mundo e com os materiais do mundo, onde se situa o artista. Envolve método e trabalho sistemático: por exemplo, o artista tem que observar e dissecar todos os detalhes de uma paisagem para, depois, com pinceladas precisas e inovadoras, retransmitir outros sentidos àquilo que se via de forma prosaica. Por isso, em geral o que chamamos de arte não se constitui apenas de formas (linhas, rimas, materiais, estilos, composições, volumes, sons, etc.); também há o trabalho de ressignificação material e 
simbólica que se plasma nas formas, e é nesse trabalho que se situa o significado de algo artístico.

Se a arte em última instância faz parte de um fazer social e, como se disse antes, ela se faz no mundo e com as coisas do mundo, isso a torna um objeto de estudo, o que ocorre de fato em diferentes disciplinas e suas categorias de análise, tais como a crítica da arte, a história da arte e a sociologia da arte (COLI, 1981). Pode-se, assim, descrever o aparecimento e os contextos da expressão artística ao longo do tempo ou lançar lentes para captar como o artista e a obra se inserem num campo de força onde a busca por lucro e prestígio fazem parte do contexto (BOURDIEU 1996).

Mas existe um "porém": esses são discursos sobre a arte e não a própria arte; são ciências que nas suas particularidades projetam sobre a arte uma visão e nela buscam encontrar racionalidades ou regras. Saber história da arte, distinguir etapas e movimentos artísticos não é a mesma coisa que se expressar artisticamente ou saber apreciar uma obra. Isso equivale a dizer que identificar uma geografia simbólica no tríptico "Jardim das Delícias Terrenas" de Hieronymus Bosch não significa se tornar sensível de forma imediata para a enorme gama de sensações e confusão de sentidos despertados nas filigranas dessa obra, o que certamente ocorre de forma diversa para cada expectador no tempo e espaço.

Essa gama de sensações inclui muitas coisas acontecendo cadenciada ou torrencialmente no corpo e na consciência. O corpo na verdade é um enorme mundo habitado por diversas formas de sensações, afetos, gostos, aversões, etc. Ou, ainda, como esclarece Eagleton (1990), “tudo aquilo enfim que se enraíza no olhar e nas vísceras e tudo o que emerge de nossa mais banal inserção biológica no mundo".

Mas o que tem a ver corpo com arte? Eis que entramos na dimensão estética. A estética tomou uma importância na compreensão da arte, pois toca de forma central na interação objetiva/subjetiva entre sujeito e as coisas que o afetam. Estar no mundo é inapelavelmente estar sujeito a ser afetado por toda 
sorte de estímulos, emoções e sentimentalidades. Estamos condenados a pensar sobre nosso meio e a sentir com ele.

Contudo, ainda que o artista e sua produção sejam parte de um movimento de construção histórica e cultural (PONTES, 2005), isso não implica que sua arte seja o espelho do mundo em que está situado. Em realidade, a mimese artística não visa espelhar o real instituído, embora dele se aproxime ou nele se ancore, mas sim despertar e abrir-se para outras realidades, além do que já está condicionado.

Em grande parte das vezes, a tendência é que disso decorra uma conclusão apressada, que precisa ser desfeita, pois se apoia numa concepção simplista e aburguesada conforme a qual a arte seria um "distanciamento" ou escapismo em relação ao mundo social. Nesse tipo de raciocínio, o poeta, por exemplo, que tem como referência o que existe na realidade (o que é inescapável), para aquilo que está no seu horizonte imaginativo e destreza poética, apenas criaria distrações, falsas ilusões, ou ainda, seus versos nada mais seriam que uma fuga da realidade presente. Pois bem, contra isso, o que dizer da lírica de Maiakovski? Então toda a sua produção nada mais é que um escapismo do mundo em que viveu e sentiu transformar-se no período revolucionário russo, ou ainda, um "Navio Negreiro" de Castro Alves, estaria fora de todo e qualquer contexto social, não é também uma crítica social?

A arte não é uma fuga do social ou uma desconexão do mundo, mas libertação do blasé, do embotamento dos sentidos, das repressões, convenções e alienações. Se há distanciamento, é aquilo que se coloca como uma subversão da consciência, cuja intensidade dissolve aquela consciência da realidade naturalizada "ao ponto de distorcer as coisas de modo que o indizível é dito, o invisível se torna visível e o insuportável explode" (MARCUSE, 2007, p. 46). Mas, deve-se insistir, mesmo que a arte tenha uma referência no social ou reflita um estado de espírito, ainda assim a arte está desincumbida de coincidir com a realidade. Isso quer dizer que o distanciamento não quer dizer fuga da tensão do 
ser com seu mundo. O que se busca é o contrário, é se distanciar do real que se impõe, deformando e/ou remodelando o real aparente.

Mas, então, como algo que não tem a pretensão de ser o espelho da realidade, que se funde no imediato ou na relação direta com a experiência, pode ao mesmo tempo revelar mais sobre ela? Que diabos de paradoxo seria este que, ao mesmo tempo em que nega, também afirma a realidade, mas de outra maneira? Ou o que faz com que a experiência estética tenha alcance conceitual? E, o mais importante para o nosso caso, como numa sala de aula pode ser possível vincular a crítica da realidade aparente com a imaginação?

Pois bem, é a imaginação a chave das questões acima, é o que permite que a intuição encontre com a razão e o particular, com o universal, ou seja, é o que faz com que o gosto, a preferência e as intuições estéticas tenham pretensão a alguma universalidade. É este justamente o problema enfrentado por Kant na Crítica da Faculdade do Juízo. A imaginação permite um livre jogo entre as intuições iii e os conceitos, ainda que a estética esteja fundada na experiência livre de conceitos (SCRUTON, 2011). Apesar de cada um ter um gosto ou experiência singular, essas experiências fazem parte de uma subjetividade humana que é universal. É a imaginação que impregna nossas experiências com conteúdo, que permite trazer conceitos e defender um juízo estético.

Como bem destacou Herbert Marcuse (2007), uma vez que a arte dá vazão ao mundo estético, como uma expressão humana desinteressada, ela exprime o que se esconde, o que é profundo, o que é reprimido, e é fazendo parte do que existe que a arte pode falar contra essa realidade aparente.

No lastro desses argumentos, a arte não visa oprimir e se constituir num argumento de autoridade, ainda que regimes políticos, religiões e agentes da propaganda possam dela se apropriar para a função ideológica, ou venham a transformá-la numa mercadoria, tal como levantaram os críticos frankfurtianos. Isso tudo são usuras, apropriações, alienações. Se a arte tem uma essencialidade, esta orbita na liberdade de explorar e expressar nossa relação com nós mesmos e com o mundo circundante. E num sentido revolucionário, ela rompe com a 
realidade mistificadora, pois ela sobrevive além dessas usurpações. Por isso as vozes se levantam quando há qualquer tentativa de enformar a arte num sistema de controle, pois, ao fim e ao cabo, é a liberdade que está sendo reprimida.

\section{A INTERFACE ARTE-GEOGRAFIA}

De antemão, a interface arte-geografia pode ter um alcance heurístico bastante amplo, instigando pesquisas em diferentes horizontes. A "geografia da arte" poderia significar, por exemplo, um tipo de pesquisa socioespacial focada nos tipos e na forma de distribuição espacial dos investimentos culturais e artísticos numa determinada região ou cidade, buscando determinar uma compreensão a partir do espaço, das classes sociais e do capital cultural. Em outra direção, a simbolização artística de certos espaços naturais, tal como expresso pelo movimento cultural Land Artiv, seria um exemplo, entre outros, daquilo que poderia se enquadrar no campo "arte na geografia". Da mesma forma, não se pode ignorar nessa relação arte e geografia, o número crescente de trabalhos geográficos que buscam reconhecer as geograficidades presentes na linguagem artística e/ou literária.

Por sua vez, a direção ou o leitmotiv para este trabalho poderia bem ser a geografia pela arte e a arte pela geografia, o que enuncia a interpenetração de ambas as esferas e a consequente abertura a outras maneiras de sentir, analisar e imaginar o espaço geográfico e naquilo que é particular e mais importa aqui, a exploração dessa interface na geografia escolar.

Uma interface já em construção e promissora, pois atualmente referências ou fragmentos artísticos e literários vêm aterrissando no conteúdo de ensino de geografia, não somente para determinar um apelo didático como para indicar uma tentativa de abertura às formas criativas de se experienciar e expressar a espacialidade. Isso não deixa de ser igualmente uma iniciativa para uma educação geográfica inter/pluridiscursiva, pois, afinal, por que delimitar a geografia somente a um único discurso e/ou única maneira de experienciar o 
espaço geográfico? Por que não investir na coexistência de discursos e métodos, enfim, enriquecer de possibilidades a disciplina escolar geográfica, dotá-la de espaços de crítica e criação?

Mas, para que esses esforços não se envidem numa ação cega e desarticulada, é necessário que o empírico também promova uma reflexão. Não é uma questão de encontrar ou inventar um discurso que sustente uma prática, até porque a prática na sua trajetória nunca está desgarrada de algum tipo de discurso e intencionalidade explícita ou implícita. A questão é outra: é a de refletir e alargar os horizontes da abordagem teórica e prática no ensino de geografia para possibilitar uma discussão. Pensar a geografia pela arte e a arte pela geografia é, em si, estabelecer uma confluência de sentidos e experiências que direcionam para uma prática educativa.

De início, o tema da arte dentro do campo disciplinar da geografia já não deveria causar estranheza ou ser visto com um exotismo. Em realidade já existem contribuições pioneiras sobre o tema a arte e a geografia (REES, 1976; VALE, 2007; KAUFMANN,2004; HAWKINS, 2013; JELLIS, 2015, entre outros). Não é um tema novíssimo (ainda que marginal), como também não está desarticulado, haja vista que, mesmo no Brasil, são cada vez mais ricas e amplas as discussões em torno da confluência arte e geografia, no campo específico da literaturav. Isso, por sinal, já vinha acontecendo bem anteriormente na geografia anglo-saxônica, sobretudo desde a década de 1970, com o aparecimento de um maior número de trabalhos também no campo literário (BROSSEAU, 2007).

E é justamente a partir dos anos de 1970 que as novas geografias adquiriram "espaço". Isso se deu em face de um duplo movimento que se batizou de spatial turn e cultural turn vi, momentos de inflexão que fizeram brotar com mais força as questões da modernidade e das diferenças no âmbito da dimensão espacial. Como consequência, essas vanguardas trouxeram uma erupção de novas possibilidades metodológicas e do reconhecimento da pluralidade socioespacial, que se traduzem em diversas esferas, como das identidades, do simbólico e do estético. Ao mesmo tempo, a perspectiva crítica se ampliou para 
os conflitos e as diferenças que se dão no e pelo espaço em várias escalas (MASSEY, 2008).

É o despertar para esse espaço multifacetado que proporciona à geografia como ciência um sentido de avanço para além das descrições facto-sensíveis do espaço, ou seja, as subjetividades e intencionalidades que estão junto e por trás das práticas dos agentes no e pelo espaço. Assim, de forma inescapável, a geografia contemporânea, sem anular o aparente, o visível e o material, também concede relevância para a exploração do subjetivo (consciência), do invisível (teórico) e do imaterial (simbólico) - aspectos que também qualificam e constituem a experiência espaço-geográfica.

Com este norte, o território da arte não poderia ficar de fora, pois nele se encontra grande riqueza de representação e tradução das geografias em diferentes linguagens (literatura, poesias, artes plásticas) e aquilo que rege tudo isso, seu centro de gravidade, ou seja, a relação material e simbólica dos homens com seu mundo. Reconhecer uma geografia modelada numa obra é identificar uma relação mediada pelos sujeitos com o meio, com o mundo circundante, um tipo de prática que incorpora tanto uma leitura da realidade como a projeta, alterando a experiência geográfica. Nessa via, a geografia numa obra não se limita a uma externalidade ou à sua representação transfigurada, mas ao trabalho do artista, sua experiência com o meio.

Com efeito, uma tela que torna plástica uma paisagem natural ou a "Paulicéia desvairada" de Mario de Andrade externalizam cores e falas onde também se reconhecem geografias. Além disso, alcançam um sentido de alteração, não da geografia na sua materialidade (pelo menos de maneira imediata), mas das nossas sensibilidades e entendimentos. Altera no sentido metafórico de cromatizar a experiência geográfica ao estabelecer semitons, escalas intermediárias, variações e possibilidades. Isso significa dizer, que nos versos, entre os versos, na sua sonoridade, no arlequinal da "Paulicéia Desvairada" vai se revelando uma experiência de cidade. Suas ruas, esquinas e lugares vão se revelando detalhes de variados tempos e momentos, sob diversas 
luzes e situações. Essas singularidades não são os arranjos espaciais, mas é a composição do próprio espaço produzido e vivenciado da sociedade. O espaço na sua densidade viva.

Daí se dizer que, num certo sentido, a geografia pela arte ou a arte pela geografia é um modo de ampliar nossa própria experiência com o espaço. De maneira mais sintética, a arte deixa fluir a dimensão estética do mundo, acrescenta ou transforma nossa imaginação geográfica - imaginação não apenas com o sentido de sonho ou fantasia, mas como síntese entre conceito e intuiçãovii.

Por exemplo, se de um lado há uma objetivação temporal e espacial na obra "Operários" de Tarsila do Amaralviii, realizada na industrialização e migração do começo do século XX em São Paulo, não se deve perder também o magma de significações que se encontram em seus aspectos simbólicos e provocativos, suscitados pelas expressões dos rostos, pelas cores e pelo volume que se combinam na mesma obra, que suscitam um intersubjetividade, uma interação simbólica calcada numa comunhão intuitiva que nos une, uma experiência que cria um lugar de encontro com sujeitos sociais no tempo e espaço.

O que se quer dizer é que há com certeza uma "geografia" nessa obra de Tarsila do Amaral ou uma geograficidade enquanto expressão de um fenômeno com um sentido espacial (SOUZA, 2013). Contudo, essa geograficidade não está somente nas referências imediatas ou interpretadas que desaguam para referências sobre as transformações do espaço, ou aquilo que liga a obra às relações objetivas do mundo. Ela também partilha de um plano consciente, autoral e intersubjetivo com um lugar, um contexto histórico e espacial. E, paralelo ou ulterior, há o trabalho artístico de conseguir dar expressividade a essas experiências, o que na verdade é um duplo e dialético processo: de uma objetivação do mundo traduzida simbolicamente, e este, expresso materialmente como obra, que a fortiori comporá uma virtualidade, portará outro modo de ver aquilo que já se tinha visto. 
De modo mais perfeito, a geografia vazada na arte permite de uma vez o encontro do social com o estético. Tal como na teoria críticaix, não se está a defender o domínio ou oposição do estético sobre a razão: ambos são vistos como constituidores das relações humanas e com a natureza (ALVES JUNIOR, 2015). É a mimese com o mundo, com sua materialidade e imaterialidade. O artista, o escritor, enfim, o trabalho do artista primeiro se faz a partir de sua inserção no meio geográfico e com o trabalho com as coisas do mundo. Há nisso tudo um modo de produção que garante alargar a experiência e a expressão das subjetividades ou, ainda, de estabelecer um espaço intersubjetivo, um encontro com o outro pela via da sensibilidade, do estético.

Até aqui se falou muito em estética e como ela se registra na arte, por que tal dimensão é importante na ligação entre geografia e arte e como ela descortina um mundo. Mas como ela pode ser explorada nas aulas de geografia? Pode-se dizer que até aqui buscamos contextualizar e justificar a interface arte pela geografia e geografia pela arte, mas é preciso avançar em seu aprofundamento compreensivo, sobretudo no âmbito da geografia escolar, o que, em si, exige um esforço mais empírico.

\section{A CONFLUÊNCIA DA ARTE E DO ENSINO DE GEOGRAFIA}

É necessário introduzir a arte e a linguagem estética nas aulas de geografia? Pensamos que as justificativas começam no importante entendimento para o aluno de que a experiência com a geografia ou uma realidade espacial concreta pode abranger campos como a ciência, a política, a cultura e o mundo das subjetividades. Além disso, a estética não está fora da geografia como se supõe: ela está presente em sua história, no trabalho das descrições do aparente, nas iniciativas de capturar o cotidiano, de provocar imaginações geográficas sobre o que é descrito. Como destaca Paul Claval (2002, p.26), “... geógrafo é uma testemunha do mundo: quando convocado a depor, tem o direito e o dever de dizer o que viu e como viveu... garantir uma autenticidade". E a expressão 
artística oferece justamente uma oportunidade de explorar essa autenticidade que é a própria experiência do sujeito com o mundo.

Contudo, há duas ideias que precisam ser questionadas a respeito não da estética em si, mas da arte no ensino de geografia. A primeira faz da arte um acessório do conhecimento geográfico, uma forma de ilustrar algumas questões temáticas que estão presentes no conteúdo escolar da geografia, em suma, um material de apoio. Estão na entrada dos temas ou em seu final, uma iniciativa que mira na contextualização do tema a ser abordado. A segunda, às vezes complementar da primeira, visa encontrar um conteúdo geográfico na arte e, nesse caso, a geografia na arte é simplesmente consumida. Ambas as iniciativas são importantes e válidas até certo ponto, mas acabam na maioria das vezes se constituindo numa visão instrumental da arte. Aqueles que fazem da arte um acessório, ignoram outras possibilidades didáticas. Perde-se a chance da liberdade estética, da experiência livre e espontânea do espaço.

Onde fica a liberdade do aluno de descrever sua experiência com outros no espaço, daquilo que vê, daquilo que é referência em sua vida diária, dos locais que frequenta, nas festas, nos shopping centers, na experiência com sua cidade, que num primeiro momento não é conceitual? Porém, o que acontece é que isso tudo frequentemente é enterrado no mundo escolar ou encapsulado como "préconceitos", "senso comum", "conceitos espontâneos". Todas essas experiências sem nomes, os gostos ou sensações precisam ser superadas ou esquecidas em prol do conhecimento científico. A ponte que liga o mundo das sensibilidades e percepções dos alunos é derrubada, tudo tem que começar de um ponto zero, pois o conhecimento dito "real" é o que pode superar o aparente e libertá-los. As singularidades são esquecidas em prol de uma universalidade reificada e unificadora, impressa num conteúdo escolar institucionalizado e que predomina como única alternativa de contato entre aluno e professor.

A entrada da arte na geografia escolar vem seguindo o mesmo caminho. 0 que se quer é ler a geografia na arte de forma objetiva, direta, buscar referências espaciais que possam ajudar a explorar os conceitos, os temas e as discussões 
em torno do espaço, mas sob uma perspectiva apenas científica e pontual. Tratase de um passo importante para a emancipação, mas aqueles que fazem da arte um acessório ignoram que ela é um meio de expressar nossa sensibilidade com o mundo, de nos despertar justamente da realidade imposta e que nos faz achar tudo comum e natural. Os alunos, pela arte, no sentido do seu fazer e não apenas como material ilustrativo, podem ser um canal de expressão espacial. Esse é o desafio, a arte como expressão de uma experiência geográfica.

Numa abordagem mais ampliada, a linguagem das artes no ensino de geografia torna possível enredar conceitos e experiências do lugar, do território, assim como é um modo de conhecimento espacial além do aparente e habitual. O que daí decorre pode gerar questões e situações de aprendizagem em que o professor encontra um rico material de discussão e momentos de intersubjetividades. Ele pode explorar as impressões dos alunos, valorizando não apenas um raciocínio espacial, mas também a imaginação geográfica.

Em suma, talvez a principal contribuição que as experiências com as linguagens da arte podem trazer no campo da geografia escolar é a de tensionar com a experiência geográfica, ou até mesmo, como destacou Massey (2017), enfrentar as contradições que fazem parte de nossas imaginações geográficas, turvar o modo a que estamos habituados, do saber tecnocientífico, muitas vezes comprometido apenas com um caminho, quando na verdade há muitos caminhos e experiências espaciais a serem imaginadas.

Apesar de transfronteiriça, há de certo modo muitos insights a serem desenvolvidos nessa interface, seja sobre o método, ao ir além da arte como mero acessório, ou sobre a prática de ensino, ao estabelecer oportunidades de se construir criativas situações de aprendizagens que possibilitem ao professor mediar oportunidades para que o aluno seja o sujeito de seu processo de aprendizado, de seu desenvolvimento formativo e crítico. As abordagens aqui desenvolvidas buscam justamente contribuir para o alargamento desses aspectos. 


\section{EXPERIÊNCIAS COM A LINGUAGEM ARTÍSTICA NO ENSINO DE GEOGRAFIA}

Ao longo dessa seção, vamos descrever duas experiências com os alunos de uma escola públicax em que foram utilizados conteúdos geográficos em interface com a arte e suas linguagens. Na primeira, conduzimos uma experiência ampla com o uso da literatura e outras referências artísticas articuladas em várias situações de trabalho. Essa experiência em particular foi desenvolvida no formato de oficina durante as aulas e nos fins de semana, aproveitando um programa da Secretaria da Educação de São Pauloxi. Já a segunda experiência foi desenvolvida durante aulas semanais de geografia, utilizando as artes visuais como linguagem de expressão do entendimento geográfico.

O trabalho com a oficina foi realizado com alunos do sétimo ano do ensino fundamental (anos finais). A ideia surgiu da necessidade de oferecer uma oportunidade nova de se aprender geografia de forma mais prazerosa, desafio constante em geografia escolar (CASTROGIOVANNI, 2000). E, para dar esse sentido prazeroso, optou-se por incentivar o exercício da leitura em relação com um conteúdo geográfico, o que poderia começar com uma aventura geográfica por meio de uma obra literária ficcional, próxima da faixa etária dos alunos desse ciclo escolar. O formato de oficina tendo curta duração e como trabalho paralelo ao feito em sala de aula nos pareceu mais viável e significativo. Essa oficina foi por nós batizada de "geoletrinha"xii, e ao final o aluno recebia um certificado de participação.

Vale dizer que o que temos chamado de oficina se deve ao uso de vários recursos, artístico-literários, como também da projeção de slides, ilustrações, mapas, globos terrestres, relacionados ao conteúdo geográfico ao longo de um tempo programado de aulas. Porém, o que de fato definiu esse formato didático foi o trabalho dos alunos, já que participaram ativa e livremente na criação e na expressão estética de suas percepções da obra ao longo dos momentos de encontro. 
Por sua vez, o formato de oficina, além de um cronograma, exige que as atividades sejam norteadas para o alcance de alguns objetivos específicos. No caso citado, o primeiro era desenvolver entre os alunos uma maior compreensão da diversidade cultural encontrada entre os povos, o que também se traduz na corporeidade dos modos de vida, tradições, gostos e religiões que ocorrem no espaço (MASSEY, 2008). O segundo era favorecer a prática da leitura e da imaginação geográfica. Afinal, entre tantas qualidades que atuam no campo estético e formativo da pessoa, também está o transportar seus pensamentos e imagens para outros lugares; não apenas reconhecer o que de geográfico está presente na estrutura da obra, mas como a geografia se plasma na trama e vida dos personagens das estórias.

Dentre tantos livros e autores que poderiam ser escolhidos, deu-se preferência para a obra de Júlio Verne, "Volta ao mundo em 80 dias". Há razões de sobra para esta escolha, entre elas uma crepitante estória, com diversas tramas e desfechos, além dos personagens carismáticos que o universo julioverniano costuma trazer. Como é bem sabido, a trama central consiste no desafio lançado aos personagens principais de se atravessar vários países do planeta no tempo estipulado de 80 dias. A trama oferece a possibilidade de se explorar as situações vividas pelo personagem, as referências geográficas e culturais, assim como alguns elementos secundários na obra, que poderiam se transformar em situações de aprendizagem e reflexão em sala de aula.

Esses elementos secundários, também denominados de "deixas simbólicas" (THOMPSON, 2011), estão sempre presentes num contexto de comunicação. Em nosso caso, eram os aspectos artísticos e geográficos de pano de fundo da obra que poderiam ser trazidos para o primeiro plano da oficina, tanto para a reflexão como nos trabalhos práticos entre os alunos. A simples referência a uma forma de religiosidade de um personagem, por exemplo, se transformava num momento de pausa para discussão sobre seu entendimento, o que alargava igualmente a compreensão cultural e geográfica da obra. 
O carro-chefe das atividades era de início a leitura coletiva de cada capítulo do livroxiii, com comentários e abertura à indagação dos alunos. A intervenção do professor consistia em elucidar partes da obra ou responder alguma curiosidade, além de direcionar os alunos para alguns pontos relevantes. Ao todo eram oito capítulos; portanto, foi uma oficina de oito aulas. Durante a leitura, havia a exposição de slides com conteúdo relacionado às ilustrações, lugares, mapas e outras imagens que enriqueciam a passagem por cada capítulo. Em seguida, os alunos eram incentivados a se expressar artisticamente quanto ao que tinham vivenciado nas aulas e a partir da leitura. Vários tipos de recursos eram disponibilizados aos alunos para a composição de seus trabalhos: lápis de cor, canetas coloridas, desenhos, recortes e outros materiais.

A prática e as estratégias desenvolvidas com este formato de aula dentro da oficina se revelaram muito frutíferas e ao mesmo tempo trouxeram muitas situações inesperadas, porém positivas. Uma das mais interessantes era com o próprio momento da leitura e a exposição de slides: surgiam muitas intervenções dos alunos, perguntas sobre significado de certas palavras, curiosidade sobre os lugares, modos de vida. Durante uma exposição de slides que mostrava os cenários de Paris na virada do século XIX, por exemplo, uma aluna, ao ver uma pintura impressionista de Monet, expressou: "Nossa! As pessoas se vestiam assim, todas de chapéu". O súbito interesse da aluna abriu a oportunidade para falarmos dos costumes de época e, sob as pinceladas e técnicas de um artista, modificam nossa maneira de pensar a realidade e ressignificar uma prosaica cena do cotidiano.

Algumas passagens da leitura fortemente impunham a necessidade de uso de material cartográfico. Essas representações cartográficas geram outras perguntas, como: "Nossa, não sabia que a França era um país pequeno!". Perguntas como essas ajudavam a trazer comparações com outros mapas e a referência para as escalas nos mapas. Além disso, os mapas projetados tinham o complemento de mapas avulsos, globos e atlas que faziam parte da oficina e que os alunos podiam manusear livremente. 
Uma das estratégias da oficina durante a leitura foi a de introduzir imagens e fotografias de época dos lugares visitados pelos personagens, o que se conseguia com a projeção de slides que retratavam pinturas, a arquitetura das cidades visitadas, além de tecnologias do período. Esse é outro aspecto que a linguagem artística oferece: compor uma narrativa simultânea de tempo e espaço.

Outra estratégia correlata àquela era a realização de um contraste de imagens da mesma cidade em épocas diferentes. Como exemplo, uma foto da cidade de Chicago no período dos personagens, ou seja, começo do século XX, e outra foto com a Chicago atual, do começo do século XXI, o que se revelou uma estratégia didática importante para o efeito de gerar interesses dos alunos nas mudanças ao longo do tempo, sobretudo como as técnicas têm profundo peso na alteração dos espaços.

Umas das atividades desenvolvidas entre os alunos consistia em traçar o curso da viagem do personagem no mapa, o que requisitava que os alunos compreendessem a posição geográfica dos países nos seus continentes, como também que criassem uma sequência temporal e espacial da rota da viagem. Na prática, os alunos tinham que recuperar algumas informações no texto e, a partir de uma folha com os traços projetados dos países e continentes, encontrar e colorir os países da viagem, assim como identificar as capitais e cidades por onde os personagens haviam feito escala. Em adição, era necessário definir os dias e horários das viagens, o que determinou a necessidade de um certo nível de entendimento dos fusos horários e movimentos da Terra. Assim, todos os passos da atividade envolviam o uso do atlas geográfico.

O trabalho coletivo dos alunos foi o cerne da oficina. Eles eram organizados em grupos e a eles eram propostas atividades em que tinham liberdade para criar, mas que serviam como um meio do professor intervir com esclarecimentos, explicações e complementações didáticas. Mas era a exposição dos seus trabalhos que constituía o momento de darem expressão e força a seus entendimentos, o que se compartilhava entre todos da oficina. 
A uma das oficinas foi possível trazer um casal de amigos que havia feito uma viagem cultural à Índia. Esses convidados trouxeram não apenas as histórias de suas experiências, como também objetos e roupas típicas daquele país. A ideia dessa atividade era que pudessem ter uma visão das percepções individuais que cada pessoa colhe do contato com outra cultura. Ao mesmo tempo, os alunos puderam interagir com os convidados fazendo-Ihes perguntas.

A atividade síntese era uma encenação teatral escolhida coletivamente. É nela que se pode reconhecer o trabalho criativo dos alunos, e, sobretudo, como os elementos conceituais e materiais das aulas e aqueles que vieram da inspiração na obra foram por eles ressignificados. E é nesse ponto que acontece a confluência de linguagem artístico-literária e linguagem geográfica: uma geografia não verbal, estética e sensível que ganha corporeidade e redimensionada pela imaginação, mas que não substitui a geografia do factual e verbal. Os alunos construíram personagens que lembravam os costumes dos povos com os quais os personagens tiveram contato, desde a cultura muçulmana, passando pela hindu até a ocidental. No dia da apresentação, não somente se vestiam de forma semelhante ao que se apresentava na história como também traziam cartazes com informações sintéticas sobre as culturas e religiões que estavam retratando em suas apresentações.

Em resumo, o que se propunha com esta primeira oficina era levar os alunos a experimentar uma viagem que, embora não material, ainda assim foi significativa em termos de percepção da diversidade cultural e de uma geografia plasmada na realidade da vivência das pessoas. A trama, com suas diversas situações, aventuras e suspense, com sua órbita em torno do desafio de dar uma volta ao mundo, não deixava de fora os conceitos comuns trabalhados numa aula de geografia, como a relação das distâncias e do tempo (fusos horários e duração da viagem), a importância das formas de transporte e mobilidade e as diferenciações tecnológicas e econômicas quando se comparam diferentes países e regiões. 
A segunda experiência ocorreu a partir de uma referência artística presente em um livro didático. Dessa referência, foi ampliada a experiência com o trabalho com artes visuais entre jovens do $9^{\circ}$ ano do Ensino Fundamental, entre 14 e 15 anos. É preciso dizer que muitas atividades desenvolvidas no ano letivo se utilizavam de textos e gráficos deste livro didático. E, tal como vem ocorrendo com outros livros e materiais didáticos, também incluía um complemento de final de cada capítulo com alusão a alguma forma de arte ou um artista de referência que relacionava seu trabalho com a geografia.

Não obstante, como já destacamos, apesar da iniciativa dos autores de incluir um complemento na área de artes ao conteúdo de geografia, nada foi acrescentado em termos de proposição de atividades. Na verdade, a referência artística, embora muito interessante, nem mesmo funcionava como um complemento do conteúdo do capítulo. Parecia mais um tipo de apêndice do que um tributário crítico ou compreensivo de tema. Em geral, essas caixas complementares de final de capítulo traziam a menção de alguns artistas e suas obras na atualidade, com uma brevíssima biografia do artista e umas poucas ilustrações de suas obras, além de uma ligeira referência a suas técnicas.

Não havia, repetimos, sugestão de atividades, nem mesmo alguma reflexão que pudesse estabelecer uma ponte entre a obra artística do autor e a geografia vivida e percepcionada pelo artista. Seja como for, ainda assim a iniciativa de trazer referências artísticas não deixavam de ser uma forma de oportunizar a possibilidade de uma compreensão mais rica do espaço geográfico por outras formas de representação. Enfim, não era o caso de descartar ou ignorar essas referências estéticas e artísticas, mas de avançar e complementá-las com um trabalho de sala de aula.

Pois bem, o trabalho desenvolvido com os alunos girou em torno das técnicas e da estética praticada pelo artista plástico e fotógrafo Vik Muniz, mencionado em uma dessas caixas complementares no livro didático. Por sorte, um painel de uma das obras desse autor sobre a cidade do Rio de Janeiro estava 
presente em uma sala de aula da escola, o que contribuiu para a exemplificação dos materiais e para explicar aos alunos o simbolismo trabalhado pelo artista.

Entre as diversas facetas que constituem as obras de Vik Muniz, destaca-se o uso em seus trabalhos de diversos materiais descartados pela sociedade, sobretudo itens encontrados em sucatas, lixo, resíduos industriais, produtos recicláveis de que o autor se utiliza para recriar fotografias ou releituras de obras icônicas. Além disso, há também experiências com os espaços degradados em que o autor revaloriza o aspecto humano e social, como o realizado com catadores de lixo no aterro sanitário de Gramacho, em Duque de Caxias (RJ), trabalho que buscou dar uma expressividade artística e social ao papel desses trabalhadores na sociedade. A reflexão e as atividades que foram desenvolvidas com os alunos centraram-se justamente na reinterpretação dos espaços urbanos, dos aspectos materiais e simbólicos presentes na vida social da cidade.

A atividade foi dividida em três etapas e organizada em grupos de alunos. Esperávamos concluí-la em seis aulas (cada aula tem cinquenta minutos). A primeira etapa consistiu em elevar o nível de informações dos alunos sobre o autor e suas obras usando reportagens e textos. A segunda etapa foi a pesquisa dos lugares degradados, sua localização, os seus aspectos econômicos e/ou simbólicos, que criou condições para que os alunos chegassem à compreensão do lugar como um espaço de vivência, trabalho e memória. A terceira etapa foi a síntese, isto é, o momento e a vez de os alunos darem vazão à sua expressão visual artística e social por meio, sobretudo, da colagem e bricolagem de figuras, desenhos, fotografias e outros materiais de que eles quisessem se utilizar.

Esta terceira etapa se revelou uma instância importante para que os alunos pudessem se posicionar diante de toda aquela materialidade encontrada em suas pesquisas. Esse momento de criação também foi um momento de pausa, reflexão e tradução de suas próprias impressões. Contudo, esse aspecto, digamos, mais abstrato e intuitivo, que é o de criar suas próprias leituras da realidade, ou seja, aquilo que perceberam dos lugares degradados, não era uma prática comum na escola, quiçá nem na vida desses jovens. Com efeito, muitas perguntas e dúvidas 
surgiam sobre como poderiam dar vazão a suas ideias e percepções. A maioria tentou apenas reproduzir os dados encontrados. Outra dificuldade foi buscar acordos entre os colegas do grupo para delinear como seria o trabalho e o que queriam que fosse representado.

Pode-se dizer que essas dificuldades foram sendo vencidas ou minimizadas, pois observávamos que é com a mão na massa que essas intuições, sensações e outras aspectos perceptivos vão se libertando, para depois serem fundidos nos materiais e no trabalho prático que faziam. Ou seja, entre uma colagem e outra, na escolha de um tema, ou mesmo de uma ideia, os alunos vão se soltando e dando suas opiniões, libertando suas imaginações.

Na terceira etapa também há os momentos em que os alunos se voltam para as experiências com os conceitos e entendimentos desenvolvidos previamente em sala de aula, porém de forma operacional. Isso se mostrou nas relações entre escalas e na definição de seus recortes de abordagem. Percebiam, por exemplo, que falar em ruas esburacadas da cidade implicava definir a priori se essa abordagem tomaria a cidade como um todo ou apenas uma rua, um bairro. Estar diante dessas opções de escala afetava também a maneira como pretendiam criar seus trabalhos visuais.

Dentre os diversos resultados apresentados pelos alunos, destacou-se o realizado por dois grupos que acabaram escolhendo a mesma cidade e o tema ambiental, mas que usaram diferentes representações e colagens. Tal resultado possibilitou trazer para a classe o quanto as experiências de lugar e sobre lugares, tais como sentir, perceber, viver e representar uma cidade, não constituem um fato consensual, mas fazem parte de escolhas arbitrárias e subjetivas. Um outro trabalho (Figura 1) também chamou a atenção: a proposta dos alunos foi criar um choque de contrastes (cores, formas e dimensões), representado nos dois planos perceptivos de uma mesma paisagem. Em realidade, conseguiram atingir um efeito polissêmico, provocar a pluralidade de significados advindos do pensar ou do intuir diversas formas de dualidades por meio da representação figurada do Taj Mahal. 
Figura 1 - Trabalho de alunos no $9^{\circ}$ ano do Ensino Fundamental.

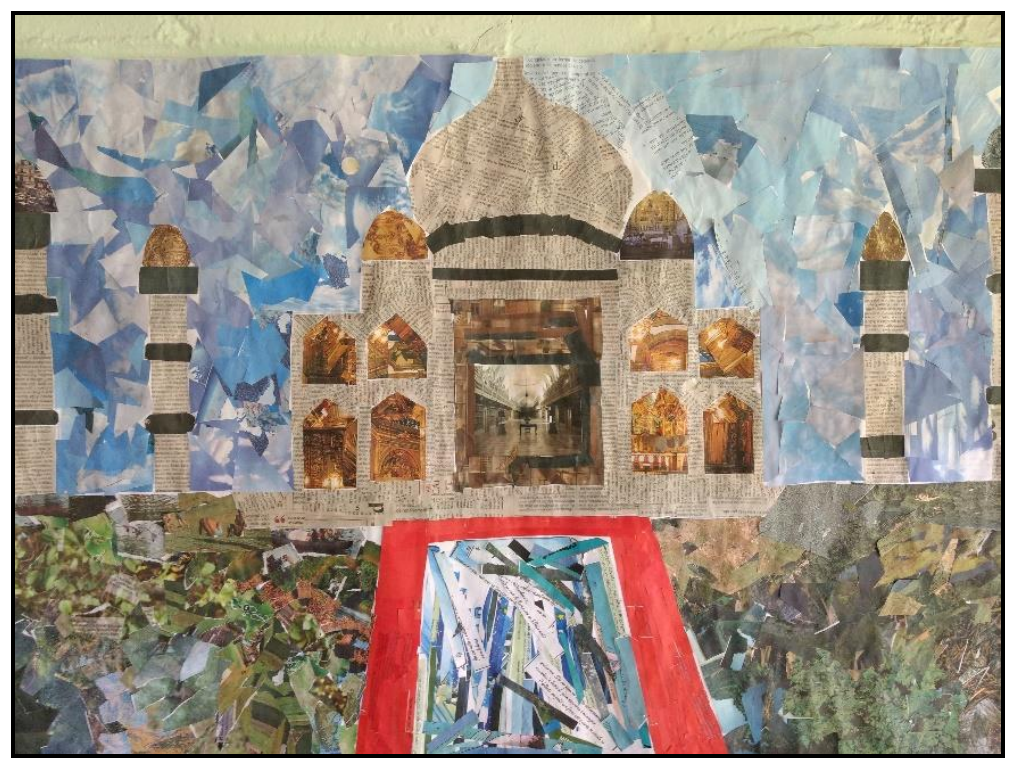

Acervo particular do autor (outubro, 2017)

É preciso salientar que fazem parte dos resultados também as dificuldades encontradas. Uma delas foi a necessidade de mais aulas do que as seis que havíamos previsto: foram dez no total. A escolha dos materiais se inspirava nas obras de Vik Muniz usando objetos descartados. Embora fosse relativamente fácil encontrar uma diversidade de materiais, já a etapa de criação se revelou um pouco mais complicada, pois nem sempre era possível para os alunos dar vazão às suas ideias criativas. O uso de garrafas plásticas descartáveis, por exemplo, foi uma ideia de alguns grupos, mas se revelou de difícil consecução moldá-las nas representações artísticas que pretendiam. Em realidade, muitos trabalhos foram interrompidos, em face do tempo e complicações, e esses alunos tiveram que buscar materiais mais flexíveis e moldáveis para suas representações.

\section{PROPOSIÇÕES FINAIS}

Inicialmente o trabalho em sala de aula no formato de oficina possibilitou maior liberdade e autonomia para se usar diferentes recursos. Um resultado pedagógico interessante é a maneira como a leitura pode se tornar um instrumento para diversas deixas simbólicas, permitindo ao professor fazer 
referência do conteúdo científico e destacar como esses conteúdos estão presentes na vida cotidiana. Por sua vez, o trabalho em sala de aula, no curso normal da rotina escolar, resultou num forte protagonismo dos alunos para realizar seus projetos, contudo, como cada grupo poderia escolher as formas de representação e uso de materiais, isso impõe ao professor, pensar também de forma criativa sobre como auxiliar os alunos em suas bricolagens. Tanto ele como os alunos precisam coadunar o que se apresenta entre o mundo objetivo e geográfico, com suas próprias interpretações e maneira como isso tudo se será representado.

Mas até onde chegaram essas oficinas e aulas? As situações e experiências com recursos artísticos levaram de fato os alunos a mudar sua visão da realidade? O uso da linguagem literária e artística pode estabelecer também uma ponte com os conceitos científicos? Obviamente que não se busca com umas poucas experiências resolver todas as indagações e problemas didáticopedagógicos que possam surgir quando a arte e geografia se fundem no ensino de geografia. São necessárias mais experiências e pesquisas, com diferentes variáveis, recursos e níveis de interação aluno-professor para se chegar a algum ponto arquimediano ou conclusivo.

Mas, apesar disso, essas experiências levaram os alunos a mostrar maior interesse pelas aulas de geografia: eles encararam o trabalho prático como momentos de prazer, sem deixar de lado a seriedade e a objetividade necessárias para a realização de suas atividades e trabalhos. Um aspecto positivo e visível desse trabalho é o fato de os alunos terem a oportunidade de exercitar a imaginação geográfica, isto é, pensar e refletir sobre suas percepções espaciais. Mas, o que mais chama a atenção foi quando os alunos experimentam a própria expressividade espacial, quando eles descobrem que têm algo a dizer sobre o mundo e se orgulham de suas criações. 


\section{OUTRAS CONSIDERAÇÕES}

O que se propôs aqui foi um compromisso, muito mais que um mero contato incidental, entre a arte e o ensino de geografia, compromisso que busca tornar possível uma abertura ao estético, pois esta dimensão faz parte da experiência geográfica: o corpo, as intuições e as sensibilidades do sujeito no espaço geográfico. Além disso, esta interface dá poderes para a expressão da sensibilidade e para o exercício da imaginação geográfica dos alunos.

Não obstante, não se pode cair na falsa ideia de que se busca uma fuga, um escapismo da arquitetura conceitual e discursiva que se constrói como uma geografia oficial, científica, formal. Não se pode ignorar essa geografia; ela é também um campo de luta e libertação. Portanto, não se busca eliminar ou estabelecer reducionismos. O que se tratou aqui foi de enunciar uma contribuição propositiva, que se realiza quando a discursividade universalizante deixa de ser um voo solitário nas aulas de geografia e se passa a reconhecer o mundo das subjetividades.

É uma ponte que deve resultar do trabalho prático do aluno, mas que depende do estimulo do professor, que está ciente de que o aluno é algo mais que um depositário de saberes, que sabe que ele é um criador de imaginação, criador de incessantes experiências com as espacialidades do mundo. A experiência da geografia não se reduz ao formalismo que se constrói a partir de uma entidade científica; aliás, nem a geografia escolar deve se reduzir a isso. A experiência dos sujeitos com a geografia está nos lugares, como também está fora deles; está na sala de aula, como também está fora dela.

As situações de aprendizagem e de sentido que foram trazidas neste trabalho devem ser vistas como tentativas para se dar expressividade a estas imaginações geográficas, de ampliar a visão dos educandos com a geografia, para que eles atentem a que a geografia não está somente próxima deles, mas está com eles, em suas passagens, nos caminhos que fazem pela cidade, nos sentidos 
e nas intuições que derivam do espaço geográfico e que ao mesmo tempo o moldam.

Dar vazão à expressividade estética e trazer a linguagem artística para a sala de aula também permitem estender uma reflexão, um debate, ou tecer até mesmo conexão com o conhecimento estruturado da geografia como ciência (MACHADO, 2007). Por isso, acreditamos que explorar a mundo estético não elimina a aproximação com o conhecimento conceitual; em realidade o coloca sob novas perspectivas, sem ocultar o sujeito que experimenta o mundo.

Por último, gostaríamos de dizer que, nas linhas e entrelinhas deste trabalho, estamos chamando a atenção para uma necessidade que é a de uma sala de aula com mais encontros e liberdade. O professor, assim como os alunos, precisam exercitar a liberdade, a autonomia e a imaginação e devem ter o direito a isso, ou seja, é preciso discutir o controle das mentes e dos corpos. A criação, a expressividade e as experiências são aspectos que paulatinamente vêm sendo abafados em sala de aula, não por culpa do professor, mas de um sistema que cada vez mais busca disciplinar absolutamente o processo de ensino, que há muito tempo disciplina o que, como e onde ensinar. E, por consequência, são as vozes da escola, dos sujeitos que a constroem no dia a dia que cada vez mais estão sendo ignoradas. São regras, metas, objetivos que visam padronizar, uniformizar a vida escolar, extinguir sua pluralidade. É uma estandardização ou absolutização do ensino que exige daqueles que fazem a geografia escolar ou que com ela estão comprometidos se insurjam.

\section{REFERÊNCIAS}

ADORNO, T. W. Teoria estética. Lisboa: Edições 70, 1993.

ALVES JÚNIOR, D. G. Como a literatura pode ser formativa? Sobre os modos de uma diferenciação mimética da razão. Impulso, p.45-54, 2015.

BOURDIEU, P. As regras da arte: gênese e estrutura do campo literário. Trad. Maria Lucia Machado. São Paulo: Companhia das Letras, 1996.

BROSSEAU, M. Geografia e literatura. In: CORRÊA, R.L; ROZENDAHL, R. (orgs). Literatura, música e espaço. Rio de Janeiro: EDUERJ, 2007, p. 7-17. 
CAPEL, H. Geografía humana y ciencias sociales: una perspectiva histórica. Montesinos editor. Barcelona, 1987.

CASTROGIOVANNI, A.C. Apreensão e compreensão do espaço geográfico. In: CASTROGIOVANNI, A.C. (org). Ensino de Geografia: práticas e textualizações no cotidiano. Porto Alegre: Mediação, 2000.

COLI, J. O que é Arte. São Paulo: Brasiliense, 1981.

CORRÊA, R. L.; ROSENDAHL, Z. Geografia Cultural: introduzindo a temática, os textos e uma agenda. In: CORREAA, R. L.; ROSENDAHL, Z. (Org.). Introdução à Geografia Cultural. Rio de Janeiro: Bertrand Brasil, 2003. p. 9-18.

EAGLETON, T. A ideologia da estética. Rio de Janeiro, Jorge Zahar editores,1990.

HARTSHORE, R. Propósitos e natureza da geografia. Trad. Thomaz Newlands Neto, $2^{\mathrm{a}}$ ed. São Paulo: HUCITEC: Editora da Universidade de São Paulo, 1978.

HAWKINS, H. Creative geographies: geography, visual arts and the making of worlds. New York: Routledge, 2013.

KAUFMANN, T. Toward a Geography of Art. Chicago. University of Chicago Press, 2004.

JELLIS, T. Spatial experiments: art, geography, pedagogy. Cultural Geographies, v. 22, n. 2, p. 369-374, 2015.

MACHADO, M. S. Implicações do realismo na geografia e no seu objeto de estudo, a geografia como materialidade, categoria da determinação do real. Geo UERJ, ano 09, número 17, v.1, 2007.

MARCUSE, H. A dimensão estética. Trad. Maria Elisabete Costa. Lisboa: Edições 70, 2007.

MASSEY, D. Pelo espaço: uma nova política da espacialidade. Rio de Janeiro: Bertrand Brasil, 2008.

MASSEY, D. A mente geográfica. Geographia, v. 19, n. 2006, p. 36-40, 2017.

PAREYSON. L. Os problemas da estética. Trad. Maria Helena Nery Garcez. Martins Fontes, São Paulo, 2001.

PONTES, G. M. D. Aspectos históricos das propostas pedagógicas de Ensino de Arte. In:

et al. (Orgs.). Livro Didático 1: o ensino de artes e educação física na infância. Natal: Paidéia, 2005. v. 1.

RAMOS, E.C.M. A confluência de uma ontologia geográfica e a dimensão estética. In: SUZUKI, J.C; COSTA, E.B; STEFANI, E.B. (Org). Espaço, Sujeito e Existência: diálogos geográficos das artes. Porta Alegre: Imprensa Livre, 2016, p.36-58.

REES, R. J. Constable and the Art of Geography. Geographical. Review. v.66, n.1, p. 59-72, 1976.

SCRUTON, R. Kant. Trad. Denise Bottmann. Porto Alegre, RS. L\&PM, 2011.

SAHR, W-D. Linguagem, imagem e o performativo: Um tour d `horizon na Nova

Geografia Cultural. Artigo disponível em: www.geog.ufpr.br/neer/anais_1_coloquio/mes as/wolf-d-saar.pdf

SEARLE, J. R. Mente, linguagem e sociedade: filosofia no mundo real. Trad. F. Rangel. Rio de Janeiro: Rocco, editora 2000. 
SOUZA, M.L. Os conceitos fundamentais da pesquisa sócio-espacial. Rio de Janeiro: Bertrand Brasil, 2013.

VALE, J. M. F. Geografia e poesia. Revista Brasileira Estudos Pedagógicos, v. 88, n. 219, p. 274-290, 2007.

\section{Notas}

' Ainda que exista uma dimensão subjetiva e artístico-cultural intrínseca aos mapas, predomina a interpretação decodificadora e técnica nas salas de aulas.

2 Vale mencionar a referência de uma entrevista do artista plástico Nelson Leirner para o canal Arte 1. Dizia que muitos dos trabalhos, jogos e brincadeiras que realiza no espaço de sua casa, embora não tenham pretensão de ser objetos de arte, podem por encanto do lugar e do interesse do mercado ser expostos numa galeria e se tornar aquilo que o artista não tinha intenção de criar, ou seja, objetos de arte.

iii O "intuitivo" é a apreensão não discursiva, imediata e direta do mundo, das sensações. A razão é o discurso, a racionalidade.

iv Também chamado de Earthwork, movimento que surgiu nos anos de 1960, sensível ao ambientalismo e como uma reação à indústria cultural e seu comercialismo. O movimento tem como centro de sua estética a integração do meio natural com a obra, a fusão arte e natureza. Por isso, não é possível que suas representações sejam expostas em galerias, a não ser por fotografias ou visita in situ.

v Vide os eventos de geografia e literatura que ocorrem já com certa regularidade no país desde 2010.

vi Sahr, (2016) assim como outros também identificam a virada linguística, que deixou vestígios na vertente humanística da geografia, tornado claro que o espaço também é um signo, tem uma função comunicativa e não apenas preso numa abordagem positivista. Em curso na atualidade, uma virada pictórica, baseada nos meios imagéticos e nas formas de comunicação no espaço geográfico.

vii Aqui me inspiro na terceira crítica de Kant

viii Por sinal, a imagem dessa tela é reproduzida em diversos materiais didáticos da geografia.

${ }^{i x}$ A Teoria Crítica faz referência aos trabalhos, manifestos e livros que se delineiam a partir da crítica à racionalidade e a cultura de massa pelos pesquisadores em torno da Escola de Frankfurt.

${ }^{x}$ Todas as experiências aqui relatadas ocorreram na Escola Estadual Walter Barretto Melchert na cidade de Bauru/SP.

xi Programa Escola da Família pela Secretaria da Educação do Estado de São Paulo em que a escola fica aberta à comunidade nos fins de semana.

xii Tanto a idealização do projeto "geoletrinha" como seu desenvolvimento com os alunos tiveram não somente minha iniciativa, como também o trabalho voluntário da professora e psicóloga Gleide de Sales Fátima Ferreira, que participou de sua elaboração e consecução. Atualmente buscamos ampliar este trabalho para outras escolas.

xiii Em função do tempo das aulas e da duração da oficina e também do despertar de interesse, optouse por uma versão reduzida e ilustrada da obra. 